\title{
Public health investigation of infection prevention and control complaints in Ontario, 2015-2018
}

\author{
G Cadieux ${ }^{1 *}$, C Brown², H Sachdeva ${ }^{3}$
}

\begin{abstract}
Background: Following an update to the provincial Infection Prevention and Control Complaint Protocol in 2015, Ontario public health units have been mandated to investigate infection prevention and control (IPAC) complaints in various settings, including those where regulated health professionals work. No surveillance system exists for IPAC complaints; therefore, little is known about their occurrence. Anecdotal evidence suggests a recent increase in IPAC complaints resulting in increased demand on public health resources.
\end{abstract}

Objectives: To describe the occurrence of IPAC complaints and lapses in Ontario in 2015-2018 and the public health response to these.

Methods: Ontario public health units were surveyed about the occurrence and key challenges of IPAC complaint investigations through closed- and open-ended questions. The survey was disseminated through the Council of Ontario Medical Officers of Health listserv. Data collection spanned February 4-28, 2019. Descriptive statistical analyses and thematic analysis of free-text responses were performed.

Results: Twenty-one public health units responded for a $60 \%$ response rate; fewer responding health units had a population size of less than 100,000. A nearly six-fold increase in IPAC complaints was found, from a total of 79 complaints in 2015 to 451 in 2018. IPAC lapses nearly tripled, with 61 identified in 2015 and 168 in 2018. Whereas variation in the number of IPAC complaints and lapses among public health units was noted, the most common IPAC lapse involved inadequate reprocessing of reusable equipment. Key challenges in investigating IPAC complaints included lack of staff expertise/training, increased workload and costs, interjurisdictional inconsistencies and lack of guidance.

Conclusion: IPAC complaints and lapses have increased in Ontario since 2015 when the Ministry of Health and Long-Term Care changed the IPAC complaint protocol. Public health units identified lack of expertise, increased workload, interjurisdictional inconsistencies and lack of guidance as challenges. Further research to confirm these findings, identify best practices to address these challenges as well as interventions to prevent IPAC lapses would be useful. Prospective surveillance of IPAC complaints, like for reportable diseases, would also be useful.
This work is licensed under a Creative Commons Attribution 4.0 International License.

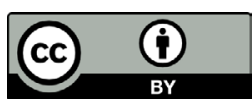

Affiliations

${ }^{1}$ Ottawa Public Health, Ottawa, ON (when this study was conducted)

2 School of Epidemiology and Public Health, University of Ottawa, Ottawa, ON

${ }^{3}$ Toronto Public Health, Toronto, ON

*Correspondence: genevieve. cadieux.ccsmt|@ssss.gouv.qc.ca

Suggested citation: Cadieux G, Brown C, Sachdeva H. Public health investigation of infection prevention and control complaints in Ontario, 2015-2018. Can Commun Dis Rep 2019;45(11):289-95.

https://doi.org/10.14745/ccdr.v45i11a03

Keywords: infection prevention and control, infection control lapse/breach, community-based health care settings, private practice/standards, ambulatory surgical procedures, cross infection/prevention and control, equipment contamination

\section{Introduction}

Recent public health investigations of complaints about infection prevention and control (IPAC) practices (hereafter: IPAC complaints) involving Ontario community health care settings have found significant deviations from best practices for reprocessing medical equipment, leading to large-scale patient notification and testing (1-3). Unlike for provincially notifiable diseases, no provincial surveillance system exists for IPAC complaints and lapses. However, anecdotal evidence suggests increased demands on public health unit resources due to an increase in the number of IPAC complaints and lapses over the past few years, as well as increasing complexity of IPAC 
investigations (e.g. involving a wide range of health care and personal service settings, and novel procedures and equipment).

The objective of this article is to describe the occurrence of IPAC complaints and lapses in Ontario community settings from 20152018 and the public health response to these.

\section{Background}

The Health Protection and Promotion Act (HPPA) (4) defines the organization of public health units in Ontario. There are currently 35 public health units in Ontario: 21 independent of local municipal government, seven regional health departments and seven health units tied into a single-tier or other municipal administration (5). Mandatory public health programs and services are defined in the Ontario Public Health Standards (OPHS) (6) and related Protocols and Guidelines. The Infection Prevention and Control Complaint Protocol (7), which was updated in 2015, mandates public health units to investigate complaints related to IPAC in a variety of settings including, but not limited to, personal service settings (e.g. nail salons, barber shops, tattoo parlours) as well as facilities in which regulated health professionals (e.g. nurses, physicians, dentists) operate. For example, of 61 IPAC complaints investigated by Ottawa Public Health in 2018, 28 (46\%) involved medical clinics, seven (11\%) involved dental clinics and 26 (43\%) involved other settings (e.g. personal service settings, allied health providers) (Personal communication, Jacqueline Willmore, Ottawa Public Health, July 8, 2019).

The Infection Prevention and Control Complaint Protocol, 2019 (7) mandates public health units to receive IPAC complaints, assess them and take steps to reduce the risk of infectious disease transmission. Response to a complaint typically involves an inspection by a public health inspector and/or nurse. They use audit tools and other resources from Public Health Ontario (PHO) (8) and various best practice documents, including from the Provincial Infectious Disease Advisory Committee (PIDAC) $(9,10)$, to assess deviations from IPAC best practices. The Infection Prevention and Control Complaint Protocol defines an IPAC lapse as a "failure to follow IPAC practices resulting in a risk of transmission of infectious diseases to clients, attendees or staff through exposure to blood, body fluids, secretions, excretions, mucous membranes, non-intact skin, or contaminated equipment and soiled items" (7). Only a small portion of IPAC complaints made to public health units turn out to be IPAC lapses; the majority involve deviations from or failure to adhere to IPAC best practices, and, based on a risk assessment, they do not represent sufficient risk of infection transmission to be considered a lapse. $\mathrm{PHO}$ is available to support public health units with complex risk assessments.

If the medical officer of health or designate determines that an IPAC lapse occurred, it must be publicly disclosed on the public health unit's website, as per the Infection Prevention and Control Disclosure Protocol (11). If an operator (e.g. person operating a personal service or health care setting) does not cooperate with the IPAC complaint investigation or implement corrective measures within the agreed upon timeframe, action may be taken under the HPPA. For example, if the medical officer of health or a public health inspector is of the opinion that a health hazard exists, a section 13 order may be used to cease a practice or the provision of a service, or close a premises.

\section{Methods}

\section{Study context, design and population}

A survey about the occurrence of IPAC complaints and lapses in Ontario community settings from 2015-2018 and the public health response to these was conducted to inform discussions during an all-day workshop about "Investigating Infection Prevention and Control Lapses in Regulated Health Settings" held at the Ontario Public Health Conference in March 2019. The study population comprised Ontario's 35 public health units. The survey was disseminated through the Council of Ontario Medical Officers of Health listserv on February 4, 2019, with reminders on February 12 and 25, 2019. The data collection period ended on February 28, 2019. Respondents needed to have access to their public health unit's IPAC complaint records to complete the survey. Responses were entered directly into an online CheckMarket $^{\circledR}$ form. Data were then extracted to a Microsoft Excel file (2010; Redmond, Washington, United States). Demographic characteristics of public health units (i.e. population size, population density per square kilometre) based on the 2016 census were obtained from Statistics Canada (12).

\section{Survey instrument}

The survey comprised a mix of closed- and open-ended questions. Respondents were asked to select their public health unit and provide for each year between 2015-2018: the number of IPAC complaints received and investigated; the number of IPAC lapses; the number of lapses where patient notification took place; the number of exposed patients notified; the number of lapses where hepatitis B virus (HBV), hepatitis $C$ virus (HCV) or human immunodeficiency virus (HIV) transmission was suspected to have occurred; and the number of HPPA section 13 orders issued. Respondents were asked to identify the method(s) used to notify patients for each of their two most recent IPAC lapses. Respondents were also asked to select from a list based on the PHO audit tool (5) the three most common types of deviations from IPAC best practices cited as the reason for an IPAC complaint, observed during IPAC complaint investigations and identified in IPAC lapses. Finally, respondents were asked to describe the three main challenges faced by their public health unit with respect to IPAC complaint investigation. The validity of the survey instrument was assessed by members of the Ontario Public Health Conference full-day workshop organizing committee. (The survey instrument is available upon request from the corresponding author.) 


\section{Analysis}

A descriptive analysis of quantitative data was performed using Microsoft Excel 2010, and open-ended responses were summarized through a thematic analysis. Given that the number of responses was higher for 2018 than for 2015, a sensitivity analysis was performed to assess if the time trends observed were due to missing data. Results from respondents who provided data for all years from 2015-2018 were compared with results from all respondents, including those with missing data.

\section{Results}

Twenty-one (60\%) of 35 Ontario public health units participated in the survey. Table 1 describes the characteristics of participating and non-participating public health units. Compared to non-participating public health units, fewer participating public health units had a population size below 100,000 and a population density above $300 / \mathrm{km}^{2}$.

\section{Table 1: Characteristics of participating and non-participating Ontario public health units (based on 2016 census data)}

\begin{tabular}{|c|c|c|c|c|c|c|}
\hline \multirow[t]{2}{*}{ Characteristic } & \multicolumn{2}{|c|}{$\begin{array}{l}\text { Participating } \\
\text { public health } \\
\text { units ( } N=21 \text { ) }\end{array}$} & \multicolumn{2}{|c|}{$\begin{array}{l}\text { Non-participating } \\
\text { public health } \\
\text { units }(\mathrm{N}=14)\end{array}$} & \multicolumn{2}{|c|}{$\begin{array}{l}\text { All Ontario } \\
\text { public health } \\
\text { units }(\mathrm{N}=35)\end{array}$} \\
\hline & $n$ & $\%$ & $n$ & $\%$ & $\mathrm{n}$ & $\%$ \\
\hline \multicolumn{7}{|l|}{ Population size } \\
\hline$<100,000$ & 2 & 9.5 & 3 & 21.4 & 5 & 14.3 \\
\hline $100,000-174,999$ & 7 & 33.3 & 5 & 35.7 & 12 & 34.3 \\
\hline $175,000-499,999$ & 7 & 33.3 & 2 & 14.3 & 9 & 25.7 \\
\hline$\geq 500,000$ & 5 & 23.8 & 4 & 28.6 & 9 & 25.7 \\
\hline \multicolumn{7}{|c|}{ Population density per $\mathrm{km}^{2}$} \\
\hline$<10$ & 5 & 23.8 & 3 & 21.4 & 8 & 22.9 \\
\hline $10-39.9$ & 6 & 28.6 & 4 & 28.6 & 10 & 28.6 \\
\hline 40-299.9 & 6 & 28.6 & 3 & 21.4 & 9 & 25.7 \\
\hline$\geq 300$ & 4 & 19.0 & 4 & 28.6 & 8 & 22.9 \\
\hline
\end{tabular}

Overall, the number of IPAC complaints increased 5.7-fold among participating Ontario public health units, from 79 in 2015 to 451 in 2018 (Table 2). The number of IPAC lapses increased 2.8-fold from 61 in 2015 to 168 in 2018; however, the proportion of IPAC complaints that were determined to be lapses decreased from $77 \%$ in 2015 to $37 \%$ in 2018 (Table 2). Of note, the number of public health units reporting this information was higher for $2018(21 / 35,60 \%)$ than 2015 (14/35, 40\%). To assess whether observed increases in the number of IPAC complaints and lapses could be attributed to more public health units reporting data for 2018 than for 2015, a sensitivity analysis was performed. Among the 14 public health units that reported data for all four years, a 5.1-fold increase in IPAC complaints (from 79 in 2015 to 405 in 2018) and a 2.6-fold increase in IPAC lapses (from 61 in 2015 to 157 in 2018) was noted; these results are nearly identical to those including the public health units with missing data.

Table 2 also shows that approximately $90 \%$ of all IPAC complaints involved at least one inspection by the public heath unit; this proportion was stable over time. From 2015-2018, $15(2.8 \%)$ of 538 IPAC lapses were assessed to pose a risk of infection transmission sufficient to require individual notification and testing. Patients were most frequently notified via a letter (7/10 public health units), press release or public service announcement (6/10 public health units) and/or through a posting on the public health unit's website (6/10 public health units). The number of IPAC lapses with suspected HBV or HCV transmission was low (4/538 lapses; $0.7 \%)$, and there was no suspected HIV transmission. The proportion of IPAC lapses where an HPPA section 13 order was issued decreased over time, from $23 \%$ in 2015 to $10 \%$ in 2018.

There was wide variation in the number of IPAC complaints and lapses investigated between public health units (Table 3 ). This was not explained solely by the size of public health units' population; the number of IPAC complaints per 100,000 population ranged from 0.9 to 62.1 (median: 9.4; mean: 12.9).

Table 2: Total number of IPAC complaints and lapses investigated by participating Ontario public health units, 2015-2018

\begin{tabular}{|c|c|c|c|c|c|c|c|c|c|c|}
\hline \multirow[t]{2}{*}{ Complaint and lapses } & \multicolumn{2}{|c|}{$\begin{array}{c}2015 \\
(\mathrm{~N}=14 \mathrm{PHUs})\end{array}$} & \multicolumn{2}{|c|}{$\begin{array}{c}2016 \\
(\mathrm{~N}=16 \text { PHUs })\end{array}$} & \multicolumn{2}{|c|}{$\begin{array}{c}2017 \\
(\mathrm{~N}=19 \mathrm{PHUs})\end{array}$} & \multicolumn{2}{|c|}{$\begin{array}{c}2018 \\
(\mathrm{~N}=21 \mathrm{PHUs})\end{array}$} & \multicolumn{2}{|c|}{ Total: 2015-2018 } \\
\hline & $\mathbf{n}$ & $\%$ & $\mathbf{n}$ & $\%$ & $\mathbf{n}$ & $\%$ & $\mathbf{n}$ & $\%$ & $\mathbf{n}$ & $\%$ \\
\hline Total number of IPAC complaints ${ }^{\mathrm{a}}$ received & 79 & 100.0 & 189 & 100.0 & 366 & 100.0 & 451 & 100.0 & 1,085 & 100.0 \\
\hline with $\geq 1$ inspection & 71 & 89.9 & 170 & 89.9 & 340 & 92.9 & 414 & 91.8 & 995 & 91.7 \\
\hline Total number of IPAC lapses & 61 & 77.2 & 108 & 57.1 & 201 & 54.9 & 168 & 37.3 & 538 & 49.6 \\
\hline with patient notification & 2 & 3.3 & 1 & 0.9 & 6 & 3.0 & 6 & 3.6 & 15 & 2.8 \\
\hline with suspected transmission of HBV or HCV & 1 & 1.6 & 0 & 0 & 2 & 1.0 & 1 & 0.6 & 4 & 0.7 \\
\hline with an HPPA section 13 order & 14 & 23.0 & 16 & 14.8 & 25 & 12.4 & 17 & 10.1 & 72 & 13.4 \\
\hline Total number of patients notified & 570 & - & $\mathrm{N} / \mathrm{S}$ & - & 703 & - & 5,112 & - & 6,385 & - \\
\hline
\end{tabular}


Table 3: Number of IPAC complaints and lapses investigated per participating Ontario public health unit, 2015-2018

\begin{tabular}{|c|c|c|c|c|c|c|c|c|c|c|c|c|c|c|c|}
\hline \multirow[b]{2}{*}{ Complaints and lapses } & \multicolumn{3}{|c|}{$\begin{array}{c}2015 \\
(\mathrm{~N}=14 \mathrm{PHUs})\end{array}$} & \multicolumn{3}{|c|}{$\begin{array}{c}2016 \\
(\mathrm{~N}=16 \mathrm{PHUs})\end{array}$} & \multicolumn{3}{|c|}{$\begin{array}{c}2017 \\
(\mathrm{~N}=19 \mathrm{PHUs})\end{array}$} & \multicolumn{3}{|c|}{$\begin{array}{c}2018 \\
(\mathrm{~N}=21 \mathrm{PHUs})\end{array}$} & \multicolumn{3}{|c|}{ Total: 2015-2018 } \\
\hline & $\begin{array}{l}\frac{c}{0} \\
\frac{0}{\circ} \\
\frac{0}{\Sigma} \\
\Sigma\end{array}$ & 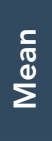 & 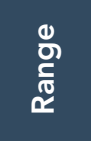 & $\begin{array}{l}\frac{c}{0} \\
\frac{0}{0} \\
\frac{0}{\Sigma} \\
\Sigma\end{array}$ & $\underset{\substack{c \\
0}}{\stackrel{0}{\Sigma}}$ & 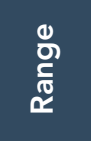 & $\begin{array}{l}\frac{c}{0} \\
\frac{0}{0} \\
\frac{0}{\Sigma} \\
\Sigma\end{array}$ & $\frac{c}{10}$ & $\begin{array}{l}\stackrel{0}{0} \\
\frac{\mathrm{C}}{00} \\
\alpha\end{array}$ & $\frac{\frac{5}{0}}{\frac{\frac{5}{0}}{0}}$ & $\underset{\substack{\frac{5}{00} \\
\mathbb{\infty}}}{\sum}$ & 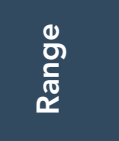 & $\frac{\frac{5}{0}}{\frac{0}{0}}$ & 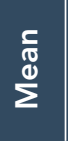 & 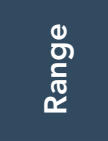 \\
\hline Number of IPAC complaints ${ }^{a}$ received & 2 & 6 & $3-36$ & 5 & 12 & $0-71$ & 5 & 19 & $0-90$ & 9 & 21 & $1-130$ & 13 & 52 & $2-278$ \\
\hline with $\geq 1$ inspection & 1 & 5 & $0-36$ & 3 & 11 & $0-71$ & 5 & 19 & $0-89$ & 8 & 20 & $1-130$ & 12 & 47 & $2-274$ \\
\hline Number of IPAC lapses & 0 & 5 & $0-36$ & 0 & 7 & $0-71$ & 1 & 11 & $0-89$ & 1 & 8 & 0-95 & 2 & 26 & $0-274$ \\
\hline with patient notification & 0 & 0 & $0-1$ & 0 & 0 & $0-1$ & 0 & 0 & $0-1$ & 0 & 0 & $0-2$ & 0 & 1 & $0-3$ \\
\hline with suspected transmission of HBV or HCV & 0 & 0 & $0-1$ & 0 & 0 & 0 & 0 & 0 & $0-1$ & 0 & 0 & $0-1$ & 0 & 0 & $0-1$ \\
\hline with an HPPA section 13 order & 0 & 1 & $0-12$ & 0 & 1 & $0-11$ & 0 & 1 & $0-11$ & 0 & 1 & $0-4$ & 1 & 3 & $0-31$ \\
\hline Number of patients notified & 0 & 48 & $0-540$ & 0 & 0 & $0-N / S$ & 0 & 47 & $0-500$ & 0 & 301 & $0-4,600$ & 0 & 304 & $0-5,140$ \\
\hline
\end{tabular}

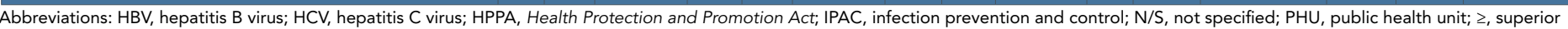
or equal to

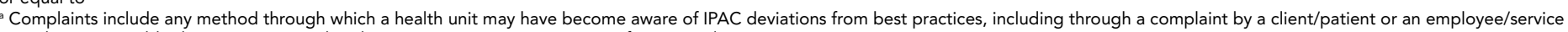
provider, a reportable disease case or outbreak report, or a routine inspection of a personal service setting

The types of deviations most frequently cited as the reason for the complaint were readily observable by clients/patients: dirty equipment (inadequate reprocessing of medical equipment), dirty environment (inadequate environmental cleaning) and lack of hand hygiene (Table 4). Inadequate reprocessing of reusable equipment and inadequate or nonexistent IPAC policies and procedures were the most common deviations identified during complaint investigation. The most frequent deviations

\section{Table 4: Top three most frequent deviations from best practices $^{\mathrm{a}}$ identified by participating Ontario public} health units $(\mathrm{N}=21)$

\begin{tabular}{|c|c|c|}
\hline \multirow{2}{*}{$\begin{array}{l}\text { Top three most common types of } \\
\text { deviations from IPAC best practices }\end{array}$} & \multicolumn{2}{|c|}{$\begin{array}{l}\text { Number of public } \\
\text { health units }\end{array}$} \\
\hline & $\mathbf{n}$ & $\%$ \\
\hline \multicolumn{3}{|l|}{ Cited as the reason for initial complaint: } \\
\hline $\begin{array}{l}\text { Reprocessing of medical equipment/devices } \\
\text { used to provide patient/client care }\end{array}$ & 20 & 95.2 \\
\hline $\begin{array}{l}\text { Environmental cleaning in the health care } \\
\text { environment where care is provided }\end{array}$ & 10 & 47.6 \\
\hline Hand hygiene & 7 & 33.3 \\
\hline \multicolumn{3}{|l|}{ Identified during complaint investigation: } \\
\hline $\begin{array}{l}\text { Reprocessing of medical equipment/devices } \\
\text { used to provide patient/client care }\end{array}$ & 16 & 76.2 \\
\hline General Policies and Procedures & 10 & 47.6 \\
\hline $\begin{array}{l}\text { Environmental cleaning in the health care } \\
\text { environment where care is provided }\end{array}$ & 6 & 28.6 \\
\hline Education & 6 & 28.6 \\
\hline \multicolumn{3}{|l|}{ Identified in a lapse: } \\
\hline $\begin{array}{l}\text { Reprocessing of medical equipment/devices } \\
\text { used to provide patient/client care }\end{array}$ & 18 & 85.7 \\
\hline Injectable medication vials or solutions & 6 & 28.6 \\
\hline Personal protective equipment (PPE) & 4 & 19.0 \\
\hline
\end{tabular}

a Based on the Public Health Ontario IPAC checklist for clinic office practice: Core Elements (8) identified in IPAC lapses were related to reprocessing of reusable equipment; use of multidose vials or solutions; and personal protective equipment.

Table 5 describes the themes identified from respondents' responses to the question "describe the three main challenges faced by your health unit with respect to IPAC complaint investigations." The top three themes identified were lack of

\section{Table 5: Key challenges of IPAC complaint investigation reported by participating Ontario public health units} $(\mathrm{N}=20)$

\begin{tabular}{|c|c|c|}
\hline \multirow[t]{2}{*}{ Themes identified } & \multicolumn{2}{|c|}{$\begin{array}{c}\text { Public } \\
\text { health } \\
\text { units }\end{array}$} \\
\hline & $n$ & $\%$ \\
\hline $\begin{array}{l}\text { Lack of expertise/training among public health unit } \\
\text { staff }\end{array}$ & 12 & 60.0 \\
\hline $\begin{array}{l}\text { Increased workload and/or costs resulting from IPAC } \\
\text { complaint investigations }\end{array}$ & 11 & 55.0 \\
\hline $\begin{array}{l}\text { Inconsistencies in IPAC complaint investigations } \\
\text { between public health units }\end{array}$ & 7 & 35.0 \\
\hline $\begin{array}{l}\text { Lack of guidance for IPAC complaint investigation and } \\
\text { lapse disclosure }\end{array}$ & 6 & 30.0 \\
\hline $\begin{array}{l}\text { Lack of support from and/or unclear role of healthcare } \\
\text { professional regulatory colleges }\end{array}$ & 6 & 30.0 \\
\hline Performing/obtaining risk assessments for IPAC lapses & 5 & 25.0 \\
\hline $\begin{array}{l}\text { Managing operators of premises targeted by an IPAC } \\
\text { complaint investigation }\end{array}$ & 5 & 25.0 \\
\hline Legal issues $^{a}$ & 3 & 15.0 \\
\hline Public disclosure of IPAC lapses and public perception ${ }^{b}$ & 3 & 15.0 \\
\hline $\begin{array}{l}\text { breviation: IPAC, infection prevention and control } \\
\text { xamples of legal challenges included: "legal liability of complaint disclos } \\
\text { tifications (e.g. Medical Officer of Health goes in a different direction fro } \\
\text { ttario [PHO] risk assessment, health unit assessing 'high risk' items in PH } \\
\text { k than described in the checklist in the context of the overall investigatio } \\
\text { en on by public health units for patient notifications" }\end{array}$ & "Sa & ower \\
\hline
\end{tabular}

CCDR • November 7, 2019 • Volume 45-11

Page 292 
expertise/training among health unit staff (60\%); increased workload and/or costs resulting from IPAC complaint investigations (55\%); and inconsistencies in IPAC complaint investigations between public health units (35\%). According to one respondent, the latter was "particularly an issue when the healthcare provider has offices in different health units." A lack of clear guidance for IPAC complaint investigation and lapse disclosure was identified as a challenge by $30 \%$ of respondents. Examples included "defining medi-spas and determining a consistent approach to IPAC lapse medi-spa investigations" and "lack of guidance for determining disclosure and/or patient notification."

\section{Discussion}

Our survey of Ontario public health units was the first to show a nearly six-fold increase in the number of IPAC complaints and a nearly three-fold increase in the number of IPAC lapses in community health care and personal service settings from 2015 to 2018. A small proportion (2.8\%) of IPAC lapses were assessed to pose a risk of infection transmission sufficient to require patient notification and testing for $\mathrm{HBV}, \mathrm{HCV}$ and HIV. There was a wide variation in the number of reported IPAC complaints and lapses between public health units; this variation was not explained solely by population size. The most common IPAC lapses investigated by public health units had to do with inadequate reprocessing of reusable equipment. The most common challenges of IPAC complaint investigations reported by public health units included lack of staff expertise/training, increased staff workload and costs, inconsistencies between public health units, and lack of clear guidance to support consistent investigations and follow-up.

We are not aware of any other published research describing time trends in IPAC complaints or lapses in community health care or personal service settings in Canada or elsewhere. Data on health care-associated HBV and HCV outbreaks from the Centers for Disease Control and Prevention (CDC) suggest that in health care settings-excluding hospitals-the number of health care-associated HBV outbreaks was highest in 2010 (linked to IPAC lapses in point-of-care glucose monitoring in longterm care settings), and the number of health care-associated HCV outbreaks was highest in 2015 (related to IPAC lapses in outpatient hemodialysis services) (13). These data, however, only reflect IPAC lapses associated with HBV or HCV outbreaks (i.e. two or more cases) and only in health care settings. The occurrence of IPAC lapses in community health care and personal service settings is likely influenced by several factors, including the increasing complexity and diversity of services provided, the entry on the market of new types of reusable devices requiring reprocessing, and the capacity of regulatory bodies, training programs and service providers to quickly adapt to these changes to ensure the safe provision of services. A possible explanation for the observed increase in IPAC complaints in
Ontario is increased awareness and reporting of IPAC issues by clients/patients and employees/service providers; this increased awareness may be related to a few highly mediatized IPAC lapses (1-3).

A strength of this survey was the ability to look at trends in IPAC complaint and lapse occurrence over time. Although the survey instrument underwent validity testing, it did not have a formal reliability assessment. Our survey participation rate was fairly high, but fewer public health units with low population size or very high population density participated; therefore, our findings may not be representative of all Ontario. Another limitation of our study was missing data for some public health units for some years between 2015-2017; however, a sensitivity analysis demonstrated that our finding of an increase in IPAC complaints and lapses over time held true when the analysis was limited to those public health units that provided data for all years. Our survey instrument did not collect data on IPAC complaints involving community health care settings separately from those involving personal service settings. Our survey was limited by the lack of detailed guidance for investigating IPAC complaints; therefore, the data collected through this survey reflects variation in the interpretation and application of Ontario's Infection Prevention and Control Complaint Protocol (7) and Infection Prevention and Control Disclosure Protocol (11). Furthermore, our survey is based on IPAC complaints and therefore likely underestimates the true burden of deviations from IPAC best practices and IPAC lapses.

Further research is needed to confirm our findings and to assess whether the increase in IPAC complaints and lapses observed in Ontario is also present in other provinces. Ideally, the occurrence of IPAC complaints and lapses would be routinely monitored through a provincial surveillance system similar to that used for notifiable diseases; such a system would assist public health in fulfilling its health protection mandate and also enable research. Our survey highlights that lack of training/expertise, increased workload, interjurisdictional inconsistencies and lack of clear guidance are important challenges that public health units face when investigating IPAC complaints.

Public health IPAC communities of practice have been set up in Ontario to assist with some of these challenges. In addition, since 2018, a Council of Ontario Medical Officers of Health working group has been examining ways to improve operational consistency for health units investigating IPAC complaints. In that context, we conducted an environmental scan of guidance documents on the public health investigation of IPAC lapses. We found explicit guidance from only two public health jurisdictions. Guidance from Québec was limited to lapses in medical device reprocessing, applicable to hospital settings, and used a quantitative or semi-quantitative risk assessment approach $(14,15)$. In contrast, guidance from the CDC was applicable to a broader range of situations and used a qualitative 
risk assessment approach (16). (Full scan results available upon request). More research is needed to identify the best methods for IPAC complaint investigation and IPAC lapse management; research findings should inform the development of clear and consistent guidance documents and tools. Research is also needed to identify effective interventions to prevent or reduce the occurrence of IPAC lapses in community settings.

\section{Conclusion}

IPAC complaints and lapses have increased in Ontario since 2015. Public health units identified lack of expertise, increased workload, interjurisdictional inconsistencies and lack of guidance as IPAC complaint investigation challenges. Further research to confirm these findings, identify best practices to address these challenges as well as interventions to prevent IPAC lapses would be useful. Prospective surveillance of IPAC complaints, like for reportable diseases, would also be useful.

\section{Authors' statement}

GC developed and analyzed the survey, contributed to the environmental scan, and was the primary author of the manuscript. CB completed the environmental scan and provided feedback on the manuscript. HS oversaw the environmental scan and provided feedback on the manuscript.

\section{Conflict of interest}

None.

\section{Acknowledgements}

The authors would like to acknowledge the Ontario public health units that participated in the survey, as well as Public Health Ontario, the Ontario Ministry of Health and Long-Term Care and the Public Health Ontario Laboratory for their support with infection prevention and control complaint and lapse investigations. The authors would also like to thank J Beehler, public health librarian, for her help in conducting the environmental scan, as well as the jurisdictions that participated in the environmental scan.

\section{Funding}

The authors received salary support from their respective organizations to carry out this work.

\section{References}

1. Willmore J, Ellis E, Etches V, Labrecque L, Osiowy C, Andonov A, McDermaid C, Majury A, Achonu C, Maher M, MacLean B, Levy I. Public health response to a large-scale endoscopy infection control lapse in a nonhospital clinic. Can J Infect Dis Med Microbiol 2015 Mar-Apr;26(2):77-84. DOI PubMed

2. Ottawa Public Health. Infection prevention and control lapse at Main Street Family Medical Centre. Ottawa (ON): Ottawa Public Health; 2019 (Accessed 2019-06-08). http:// www.ottawapublichealth.ca/en/public-health-services/ ipac-lapse-2018.aspx

3. Middlesex-London Health Unit. Infection prevention \& control lapse at ParaMed Clinics. London (ON): Middlesex-London Health Unit; 2018 Aug 20. https://www.healthunit.com/ipac-lapse-paramed

4. Government of Ontario. Health Protection and Promotion Act, R.S.O. 1990, c. H.7, Ontario, (1990). Toronto (ON): Government of Ontario (Accessed 2019-09-07). https://www.ontario.ca/laws/statute/90h07

5. ALPHA. Milestones and history: History of public health units in Ontario. Toronto (ON): Association of Local Public Health Agencies (Accessed 2019-09-07). https://www.alphaweb. org/page/milestones

6. MOHLTC. Ontario public health standards: Requirements for programs, services, and accountability. Toronto (ON): Ministry of Health and Long-term Care; 2018 (Accessed 2019-09-07). http://www.health.gov.on.ca/en/pro/programs/ publichealth/oph_standards/docs/protocols_guidelines/ Ontario_Public_Health_Standards_2018_en.pdf

7. MOHLTC. Infection prevention and control complaint protocol, 2019. Toronto (ON): Ministry of Health and Long-term Care; 2019 (Accessed 2019-09-07).

http://www.health.gov.on.ca/en/pro/programs/publichealth/ oph_standards/docs/protocols_guidelines/IPAC_Complaint_ Protocol_2019_en.pdf

8. Public Health Ontario. IPAC checklist for clinic office practice: core elements. Toronto (ON): Public Health Ontario; 2018 (Accessed 2019-09-07).

https://www.publichealthontario.ca/-/media/documents/ checklist-clinical-office-core.pdf?la=en

9. Provincial Infectious Diseases Advisory Committee. Infection prevention and control for clinical office practice. Toronto (ON): Public Health Ontario; 2013 (Accessed 2019-09-07). https://www.publichealthontario.ca/-/media/documents/ bp-clinical-office-practice.pdf?la=en

10. Provincial Infectious Diseases Advisory Committee. (2013). Best practices for cleaning, disinfection and sterilization of medical equipment/devices in all health care settings, 3rd edition. Toronto (ON): Public Health Ontario; 2013 (Accessed 2019-09-07). https://www.publichealthontario. $\mathrm{ca} /$-/media/documents/bp-cleaning-disinfection-sterilizationhcs.pdf?la=en 
11. MOHLTC. Infection prevention and control disclosure protocol, 2019. Toronto (ON): Ontario Ministry of Health and Long-Term Care; 2019 (Accessed 2019-09-07). http:// www.health.gov.on.ca/en/pro/programs/publichealth/oph_ standards/docs/protocols_guidelines/Infection_Prevention_ and_Control_Disclosure_Protocol_2019_en.pdf

12. Statistics Canada. Health profile: health region - Ontario: public health units. Ottawa (ON) (Accessed 2019-0903). https://www12.statcan.gc.ca/health-sante/82-228/ search-recherche/lst/page.cfm?Lang=E\&GeoLevel=PR\&GEO $\mathrm{CODE}=35$

13. CDC. Healthcare-associated hepatitis B and C outbreaks ( $>=2$ cases) reported to the Centers for Disease Control and Prevention (CDC) 2008-2017. Atlanta (GA): Centers for Disease Control and Prevention. https://www.cdc.gov/ hepatitis/outbreaks/pdfs/HealthcarelnvestigationTable.pdf
14. Centre d'expertise en retraitement des dispositifs médicaux. Démarche lors d'un bris de retraitement des dispositifs médicaux critiques et semi-critiques dans les établissements de santé. Quebec (OC) : L'Institut national de santé publique du Québec; 2016. https://www.inspq.qc.ca/sites/default/ files/publications/2196_bris_retraitement_dispositifs_ medicaux.pdf

15. Ministère de la santé et des services sociaux. Guide à I'intention des établissements: responsabilité et gestion d'un évènement indésirable lié au retraitement des dispositifs médicaux réutilisables. Quebec (QC) : Gouvernement du Québec; 2013. http://publications.msss.gouv.qc.ca/msss/ fichiers/2013/13-209-02W.pdf

16. CDC. Steps for Evaluating an Infection Control Breach. Atlanta (GA): Centers for Disease Control and Prevention (Accessed 2019-09-07). https://www.cdc.gov/hai/outbreaks/ steps_for_eval_ic_breach.html

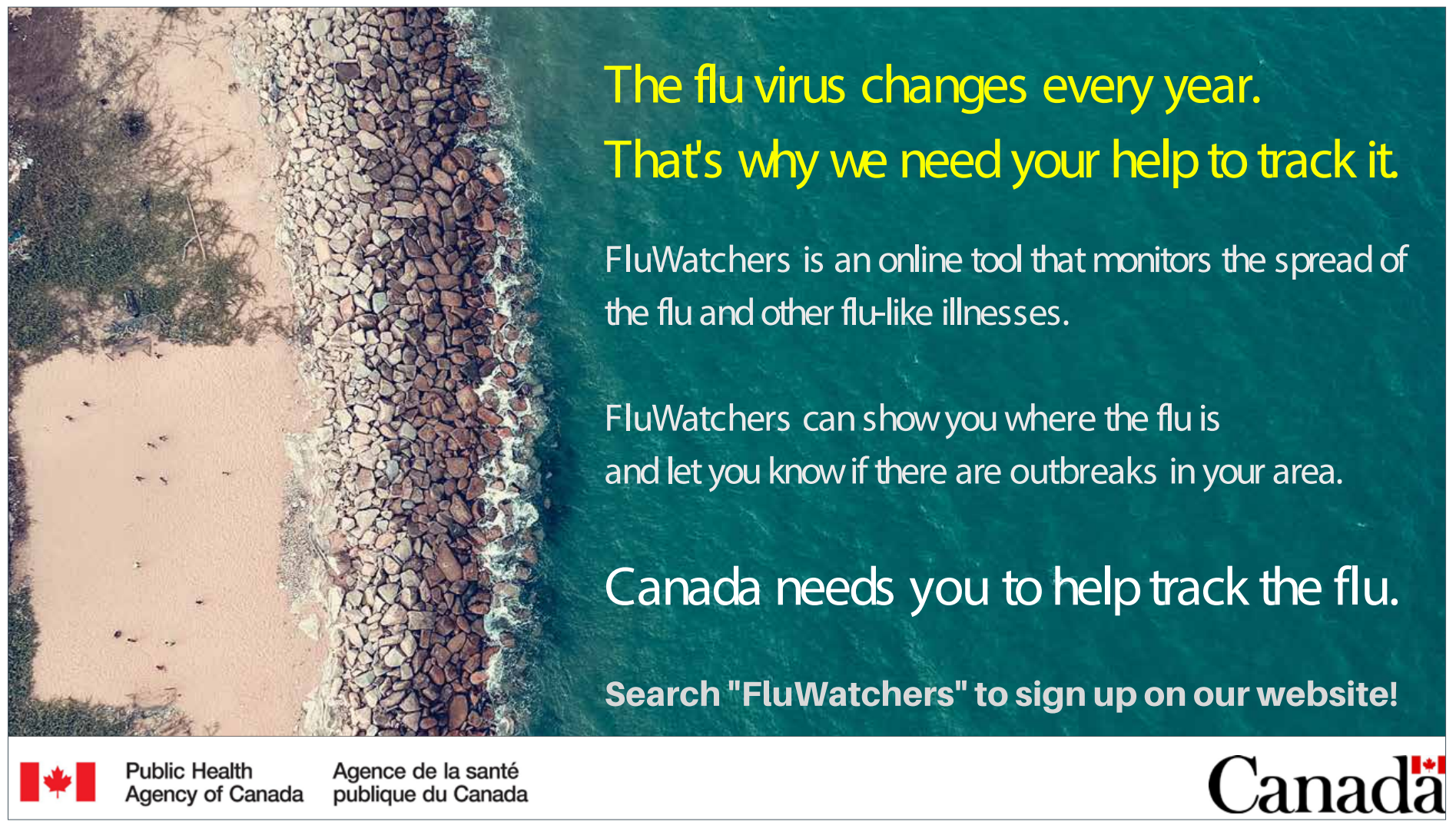

